\title{
SCAFFOLDING TUTORING STRATEGY ON VIRTUAL ENVIRONMENTS FOR TRAINING
}

\section{SCAFFOLDING COMO ESTRATEGIA DE TUTORÍA EN ENTORNOS VIRTUALES DE ENTRENAMIENTO}

\author{
Angélica de Antonio Jiménez ${ }^{1} \quad$ Brunny Troncoso Pantoja ${ }^{1,2}$ \\ Recibido el 14 de septiembre de 2006, aceptado el 26 de noviembre de 2007 \\ Received: September 14, $2006 \quad$ Accepted: November 26, 2007
}

\begin{abstract}
RESUMEN
Las capacidades conversacionales de un agente pedagógico (la personificación del entrenador) permiten una interacción social con los aprendices; luego, su aplicación en entornos virtuales 3D para el entrenamiento permite mejorar esta interacción y da mayor realismo al entrenamiento virtual, permitiendo cambios en las estrategias de tutorías que acercan la experiencia virtual a una real.

Scaffolding emerge del trabajo de famosos educadores como un paradigma instruccional y cada vez se utiliza más en aplicaciones educativas soportadas por computadores. Por supuesto, la aplicación de scaffolding en entornos virtuales de entrenamiento es muy diferente de su concepción original y de su aplicación en la sala de clases. Las características de los entornos virtuales, la personificación del agente pedagógico y sus posibilidades de interacción virtual con el alumno hacen posible la utilización de esta estrategia caracterizada, entre otras cosas, por su adaptación al rendimiento del aprendiz y su utilización dinámica de las herramientas disponibles.

Este artículo presenta las ventajas de utilizar scaffolding en entornos virtuales de entrenamiento como estrategia de tutoría para agentes pedagógicos, centrándose en las características claves de scaffolding y en cómo éstas pueden ser aplicadas en las actividades del agente pedagógico. Para modelar la estrategia, se utiliza la Teoría de la Actividad, así como los roles y objetos de aprendizaje reutilizables diseñados por contrato. Finalmente, se presenta una propuesta para aplicar scaffolding como estrategia de tutoría para agentes pedagógicos en entornos virtuales de entrenamiento utilizando el denominado "Modelo para la Aplicación de Entornos Virtuales Inteligentes a la Formación".
\end{abstract}

Palabras clave: Scaffolding, estrategia de tutoría, agente pedagógico, entorno virtual para entrenamiento.

\begin{abstract}
Because the conversational capabilities of pedagogical agents (embodiments of trainers) allow social interactions with learner(s), their application in $3 D$ virtual environments for training, besides improving the interaction and giving more realism to virtual training, permits changes in tutoring strategies bringing closer the virtual experience to the real one. Scaffolding emerges from the work of some famous educators as an instructional paradigm and it is becoming more and more used in computer-based education. Of course, scaffolding application on virtual environments for trainings is very different from its original conception, and its application in a classroom. Virtual environments for training features, the pedagogical agent embodiment, and its possibilities of virtual interaction make possible the use of this strategy characterized by its adjustment to learner's performance and its dynamic use of work tools, among others.

This article explores the advantages of using scaffolding on virtual environments for training as a tutoring strategy for pedagogical agents, focusing on the key features of scaffolding and how they can be applied in pedagogical activities. Activity Theory as well as roles and reusable learning objects design by contract are used to model our proposal. Finally, one procedure to apply scaffolding as a tutoring strategy for pedagogical agents in virtual environment for training designed using the "Model for Application of Intelligent Virtual Environments to Formation" is proposed.
\end{abstract}

Keywords: Scaffolding, tutoring strategy, pedagogical agent, virtual environments for training.

\footnotetext{
1 Facultad de Informática. Universidad Politécnica de Madrid. Campus de Montegancedo s/n. CP 28660. Boadilla del Monte. Madrid, España. E-mail: angelica@fi.upm.es

2 Facultad de Ciencias Empresariales. Universidad del Bío Bío. Avda. Collao 1202. Concepción, Chile. E-mail: btroncos@ubiobio.cl
} 


\section{INTRODUCTION}

Scaffolding might be an appropriate teaching strategy because it proposes giving the students the needed help, allowing them to use what they know and progressively making them independent to do the task. Even if we already know that scaffolding techniques can be used in a classroom in several ways, we want to focus on its use as a teaching strategy for pedagogical agents (Pas) in virtual environments for training (VETs).

"Virtual Environments (VE's) offer the potential for users to explore social situations and 'try out' different behaviour responses for a variety of simulates social interactions" [1]. The use of VETs is a promising option for educational activities, especially in those situations where traditional education can be costly, dangerous or even impossible to realize.

Scaffolding was firstly formulated by Wood, Bruner and Ross in 1976 [2]; closely related to Vygotsky's social theory [3], it was evolved essentially to explain (and help) children education. Now, our working hypothesis is that the principles and bases of scaffolding could be extended to adult training in VETs. Scaffolding is a strategy formulated to be applied by an advanced partner, who could be an instructor, the teacher, a peer, etc; because we are talking of VETs, we will assign the role of this advanced partner to the PA, the embodiment of the tutoring system in the training environment.

The proposed model is meant to work over the multi-agent architecture for Intelligent VETs presented by de Antonio, Ram'rez and Méndez [4]. All explanations about the model are related to it; anyway, by its features, the model could be easily applied over other architectures.

Figure 1 shows this agent-based architecture, which has five main agents associated to the five key modules: a Communication Agent; a Student Modelling Agent; a World Agent; an Expert Agent; and a Tutoring Agent. Each of these agents may relate to, communicate with and delegate some tasks to other subordinate agents.

The Communication Agent will delegate on: a set of Individual Communication Agents dedicated to each student; a set of Device Agents to manage the different devices that can be used to interact with the environment and make the system independent of any specific combination of interaction devices and; a Connection Manager Agent which is responsible of coordinating the connections of the students.

The Student Modelling Agent is assisted by: a Historic Agent, which is responsible of registering the history of interactions among the students and the system; a
Psychological Agent, which is responsible of building a psychological profile of each student; a Knowledge Modelling Agent, responsible of building a model of the student's current knowledge and its evolution and; a Cognitive Diagnostic Agent, which is responsible of trying to determine the causes of the student's mistakes.

The World Agent is related to: the Objects and Inhabitants Information Agent, which has knowledge about the objects and the inhabitants of the world; and the Path Planning Agent, which is capable of finding paths to move along the environment without colliding with objects or walls.

The Expert Agent is related to other agents that are specialists in solving problems related to the subject matter that is being taught to the students, at least one Simulation Agent and one Planning Agent, both capable to apply intelligent techniques in problem solving.

The Tutoring Agent, finally, will be assisted by: a Curriculum Agent, which has knowledge of the curricular structure of the subject matter; and several Tutoring Strategy Agents, which implement different tutoring strategies.

\section{THEORETICAL FOUNDATIONS}

\section{Scaffolding}

A scaffold is a temporary structure that physically supports workers while they complete jobs that would otherwise be impossible; when the work has finished, the scaffold is removed. The instructional scaffolding metaphor is used to describe a teaching strategy and some kinds of supports offered to the students in their interaction with teachers, tutors and partners when they are in a learning activity, focusing on the effective intervention of an "advanced partner". This metaphor is attractive for VETs because it focuses the attention at the trainer role in the apprenticeship process, and makes emphasis in each student individually. In VETs, PAs can play this role until the students become autonomous.

Our "scaffolding on VETs" proposal is based on different scaffolding features defined by distinguished authors, who are:

Vygotsky's Social Theory [3] who defines four main steps: Modelling the task, a demonstration with additional verbal comments; skill imitation, where the student tries to imitate the skill modelled, the tutor offers assistance and feedback, and applies frequent assessments; remove Scaffolds, when the tutor offers progressively less assistance, removing (gradually) the scaffolds; achieve expert levels, at this level the student has an expert level and doesn't need help at all to do the task. 


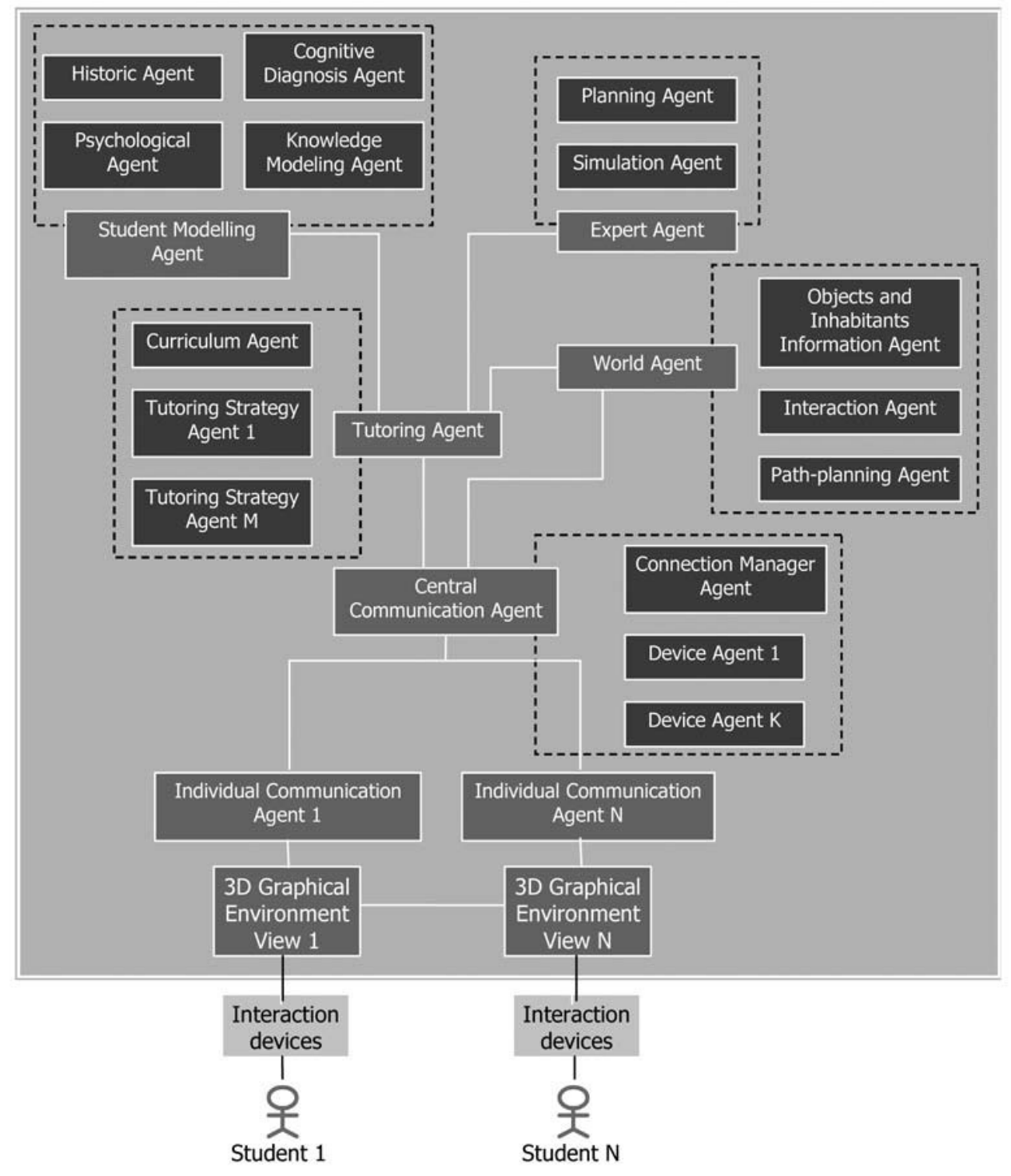

Figure 1. Agent based architecture.

Hogan and Pressley [5] describe the following features: Modelling of desired behaviour, the "teaching behaviour that shows how one should feel, think or act within a given situation"; Offering explanation, "explicit statements adjusted to fit the learner's emerging understandings about what is being learned (declarative or propositional knowledge), why and when it is used (conditional or situational knowledge), and how it is used (procedural knowledge)"; Inviting student participation, provide to the student the learning experience, especially at the beginning of the training. The invitation could be asking him/her directly, giving her/him cues or ideas, etc; Inviting students to contribute clues, to contribute with his/her ideas to the topic or the skill. The tutor could assess the contribution, and give the appropriate feedback; Verifying and clarifying student understandings is essentially offering affirmative feedback to reasonable understandings, or corrective feedback to unreasonable understandings.

Wood, Bruner and Ross [2] establish six features: Recruiting interest, firstly the tutor must "enlist the problem solver's interest and adherence to the requirements of the task"; Reducing degrees of freedom (by simplifying the task), reducing the alternative movements during skill acquisition as essential to focus attention and give correct feedback; Direction maintenance, the tutor "has the role of keeping (learners) in pursuit of a particular objective (and) making it worthwhile for the learner to risk a next 
step"; Marking critical features, the tutor's comments "provide information about the discrepancy between what the child has produced and what he would recognize as a correct production; Frustration control, the tutor may provide a partial solution to reduce stress avoiding to create dependency on the tutor; Demonstrating, "often involves an "idealization" of the act to be performed and it may involve completion or even explication of a solution already partially executed by the tutee himself... in the expectation that the learner will then "imitate" back in a more appropriate form".

According to Vygotsky [3], the zone in which the student can solve problems with external help (because $\mathrm{s} / \mathrm{he}$ is ready to capture new contents) is called Zone of Proximal Development (ZPD), and is formally defined like the distance between the actual development level (determinated by the student independent grade of problem solving) and the possible development level (determinated by the student grade of problem solving with advanced help) $[6,7]$.

Scaffolding allows the student to achieve his/her own goals; this requires adequate and different learning activities, and enough assistance (in quality and quantity) to make him/ her confident and autonomous. Currently, scaffolding is not just restricted to human-human interactions, "artefacts, resources, and environments themselves are also being used as scaffolds...the scaffolding construct is being applied more broadly, to include the support provided in technology tools, peer interactions, and discussions aimed at the whole class"[8]. "Building scaffolding into software offers the opportunity to provide for diversity through individualized support that accommodates learners of different skills, backgrounds, and learning styles, and to support growth by making more powerful functionality available as the learner develops expertise" [9].

\section{The activity theory (AT)}

AT is a cross-disciplinary framework for the study of developmental processes where a person is shaped by and shapes their environment through activities: people work to achieve their goals by transforming the social and material world that surrounds them $[10,11]$. Vygotsky, Leontiev and Luria showed the role of society in shaping the mind of the person, and developed in this way the basis of the theory. AT says that all human activities are mediated by culturally created signs or tools; through external interactions with these signs the inner mental state of the person is transformed, the knowledge is interiorized [11].
In AT context is an activity system which "integrates the subject, the object and the instruments (material tools as well as signs and symbols) into a unified whole. Activity is driven by a collective object and motive, but it is realized in goal-oriented individual and group actions" [12].

Activity is defined by the object of the activity, which describes what the individual or group is trying to achieve and what outcome they are working towards. Activity is a motive-driven process and consists of objective-driven actions and opportunity-driven operations (see figure 2) $[11]$.

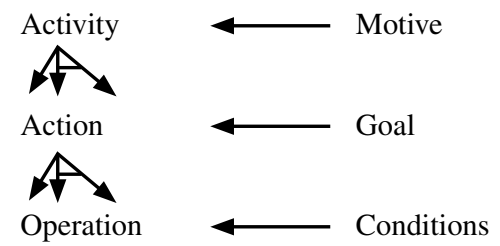

Figure 2. Activity decomposition.

Inside the activities are actions which are performed in order to meet specific goals $[11,13]$. The action concept from AT is similar to the task concept from HCI literature [11], we will use it indistinctly from now on.

Actions/tasks are composed of operations that are behaviours executed without conscious effort because they are well learned [11].

The Engeström's mediational structure of an Activity System (see figure 3), allows us to visualize the relations and interactions between the different components of AT: subject, object, tools, community, rules and division of work [10, 12-14].

AT provides a powerful framework for studying and understanding human activities. In a VET, we can use AT to study the training activities as a system, analysing their components and relationships, in order to design, model and support their implementation.

\section{Roles and RLO design by contract}

Learning objects (LOs) are "independent and selfstanding units of learning content predisposed to reuse in multiple instructional contexts" [15]. Designed in a high level of abstraction, a LO can be a reusable LO (RLO) having functionality, independence from use and strong performative ability, making possible the RLOs association for instructional proposes. 


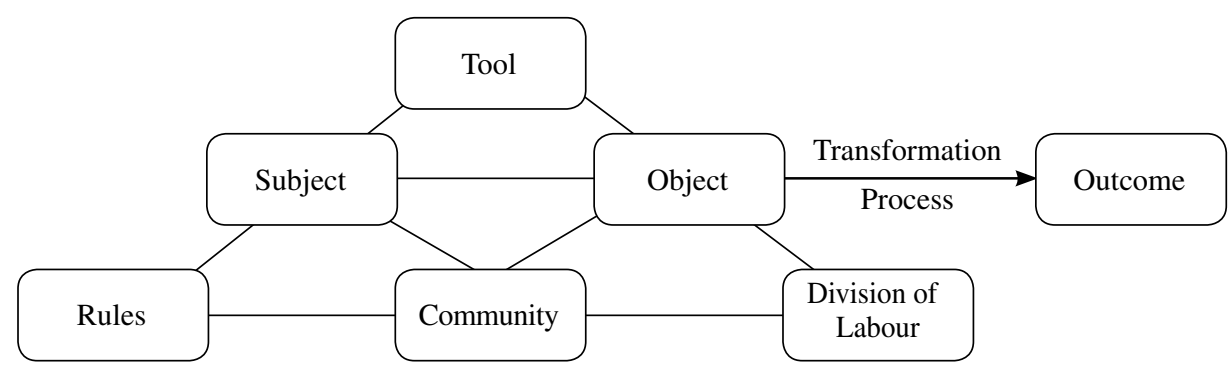

Figure 3. Engeström's mediational structure of an Activity System [3].

On the other hand, design by contract is a technique from object-oriented software engineering [16] used as the basis for the LO design by contract proposal [17, 18] a formalization of LO metadata which allows stating by contract "the conditions under which a learning object can be used and the outcomes that might be expected from its use" [17]. Originally created to be used on e-learning applications, we want to apply it in VETs.

The proposed syntax to write RLO by contract is $[17$, 18]:

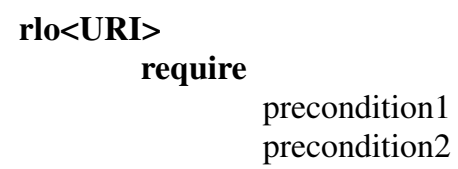

postcondition 1

pre- and post-conditions are defined by assertions according to the syntax [17]:

\section{[level] preconditionId.element <relationalOperator> requestedValue postconditionId.element $<$ relationalOperator $>$ value $[\theta]$}

where pre-and post-condition identifiers match to the learner (lrn), or the learning context (ctx), or the system where the learning object is due to be executed (sys); element maps to a LO element entry [19]; and level indicates the strength of the precondition (mandatory, recommended or optional) $[17,18]$.

Roles define who participate in a specified action/task and "are not concrete persons, but idealizations that characterize the interaction of an outside user" [18]. In e-learning a user can play different roles which can be organized into groups and can be related to other roles in different ways; because of that, Sánchez-Alonso and Sicilia [17] have extended the LO design by contract concept to reflect the role-user relationship.
In a role contract, the preconditions are a combination of the preconditions of the actions/tasks to be completed by that role and the post-conditions will be the sum of the learning outcomes of the performed actions/tasks. The role contract is defined by [17]:

\section{Role $<$ URI $>$ \\ require}

<list_of_preconditions >

ensure

$<$ list_of_postconditions $>$

\section{RELATED WORKS IN TECHNOLOGY SUPPORTED SCAFFOLDING}

Currently, there have been some attempts to apply these principles using computer technology in different ways:

Luckin and du Boulay [6] applied a Vygotskyan framework to build Ecolab, an interactive learning environment designed to help children to learn about alimentary chains; they crystallize the ZPD concept building a ZAA (Zone of Available Assistance), describe the quality and quantity of the help available to the partner to assist the learner, and a ZPA (Zone of Proximal Adjustment), that represent an appropriate selection from the ZAA for the actual learner state.

Derived from empirical work, Quintana, Krajcik and Soloway [20] present a "Scaffolding Design Framework", with scaffolding guidelines, examples and features to help designers develop effective scaffolded tools. They have attended the development and application of software tools that support learners by embedding "scaffolding" characteristics and with human teacher assistance.

Likewise, Petsangsri [21] investigated the effects of a embedded scaffolding strategy on knowledge acquisition in a Cognitive Flexibility Hypertext, defining scaffolding functions for an instructional courseware. 
Kerr [22] applied scaffolding techniques, with human teacher assistance, in 2D-VEs developed to encourage social-skills learning in adolescents with Asperger's Syndrome. The VEs have both: different levels of difficulty and a system feedback which tells the learner whether they have performed a task correctly or not.

Winnips [7] proposes a complete instructor guide to apply Scaffolding in www-based courses, based in models experimentally tested with undergraduate students, and described in his "Scaffolding by Design applied in wwwbased environments" Ph.D. dissertation.

There are more scaffolding applications; it is not our intention to examine every one, but to present an overview. Researches have agreed that scaffolding is a useful strategy to increase the learner's development of new skills and knowledge, giving her/him self-confidence. Most of the work is oriented to the development of scaffolds that work as support of learning, forgetting the principles and steps of the theory [8], mainly because its application many times is in a class-room and the students has human teacher assistance. In a VET, however, frequently the learner is an adult and the training is an individual and isolated work; the PA was born essentially to satisfy this tutoring need.

\section{SCAFFOLDING TOOLS IN VETS}

Effective apprenticeship contexts are those ones which immerse the student in a situation, and require him/her to acquire new skills and knowledge to be able to solve a specific problem, or manipulate a certain situation. In a VET, the student can immerse him/herself into a graphical learning environment, which represents the real environment in which the student will have to do the real task. Each student will be provided with a particular view of the environment, he/she will be represented with a graphical avatar with the point of view located on the avatar's eyes, and the object-interaction will be realized mainly with the avatar's hands. Submarine operation, nuclear plant operation, devices building and others can be good examples of this kind of environments.

The PA embodiment allows the virtual social interaction; in this way the instruction strategies based on Vygotsky's social theory -like scaffolding strategy-could be applied in these simulated worlds. The associated benefits are well known: a fluid communication, more and better use of the application, more attentiveness and memorization of topics, etc.

The scaffolding teaching strategy, and its apprenticeship's model, focuses on the social interaction to extend the learner's cognitive process. The understanding of new knowledge is built (by the student) over his/her previous knowledge, always helped by an advanced partner who introduces available conceptual tools from society, and fades out the support at the time that the student improves in the task. To apply correctly the scaffolding strategy on a VET it is necessary to have collaborative assistance of an advanced partner, role that is adequately played by the PA.

In a VET, the PA establishes a virtual social relationship with the student, s/he can see it, ask it for explanations to his/her doubts and talk to it. From this point of view, it -virtually- fulfils the Vygotsky's premises; on the other hand, tutorial interventions should allow the student to learn at his/her own speed, asking for help when needed and discarding it when s/he feels confident. The scaffolds will be removed both when the PA takes note of the student's progress and decides that its intervention is not necessary, or because the student him/herself requires less support (as s/he gains confidence and autonomy)

The PA -embodied and immersed in the VET- can use some scaffolding tools (scaffolds) or encourage the student use of it in their interaction with her/him:

- Direct Tutoring: it is possible to acquire knowledge directly from the PA, who presents the learning material, executes task demonstrations, invites the learner to do some activities, makes suggestions and comments if it's necessary, and applies frequent assessments to check the student's advance. The PA would answer direct questions from learners, solving doubts and focusing them to self-reflection by new questions $o$ suggestions.

- Partners support: the dialog with virtual partners facilitate the collaborative solving of problems. Technological support is given in VETs by virtual face-to-face talks. This tool encourages the cognitive change by partner cooperation and reciprocal learning.

- Guided Reflection: the PA-student dialog allows the articulation of the acquired knowledge in a way it can be used correctly in solving a problem. The embodiment of the PA, and its conversational capabilities, are very important for this.

- Shared resources: it is possible (and convenient) to have in the VET one or more specialized libraries, frequently asked questions, on-line help, or other materials which facilitate the student self-regulated apprenticeship allowing him/her to go deep into the knowledge for a possible meta-cognitive process. 
- Personal binnacle: Virtual environments can offer the student the possibility to review their personal learning binnacle, raising the student consciousness about their own apprenticeship, internalizing it in this way.

- Group process management: a VET needs virtual interaction management mechanisms, which allow collaborative problem solving.

Additionally, the PA has supplementary student's information available to define its action lines; it is obtained from the student's model: knowledge model, dedicated time by topic, student-do-nothing time, failure times, and others. The PA should be capable of integrating adequately these tools and the available information, to offer the best support to the student.

Throughout the next section we will explain how Scaffolding can be applied as a teaching strategy for PAs in VETs.

\section{A SCAFFOLDING TUTORING STRATEGY FOR PAS IN VETS}

Focusing in a single PA-student interaction for training specific activities -freely chosen by the learner- and based on the scaffolding techniques and stages previously defined, we propose a general procedure to apply a scaffolding tutoring strategy for a PA acting on a VET, illustrated in figure 4.

A problem in the application of scaffolding is how to give the learner just the needed help at the correct time; the answer we propose requires maintaining an actualized ZPD and SKM (Student Knowledge Model) for him/her. In our multi-agent architecture, the Student Modelling Agent will be in charge of building both the SKM and the ZPD.

Now, if we focus on the student like a subject of training activities in a VET, we can study it like an activity system, identifying components and relationships, useful information to define the appropriate model components.

Students in a VET have a motive to train: they want to improve some skills and/or acquire new knowledge and abilities. The VET offers different kinds of activities and the trainer must be able to suggest the student which ones are both most appropriate to his/her experience level and in agreement to the learning structure previously defined.

Our scaffolding tutoring strategy for a PA in a VET has the following steps:

1. Starting the learning activity: The student starts his/ her learning activity and we need to define correctly the
ZPD and the SKM models. If a new learner tries to initiate an activity in the VET, the Connection Manager Agent asks for the student's name or identification (just the first time in the session) and informs the Tutoring Agent. The Student Modelling Agent starts with student's diagnosis -using its sub-agents- and determines his/her SKM and $\mathrm{ZPD}$, in a way below described, and informs the outcomes to the Tutoring Agent.

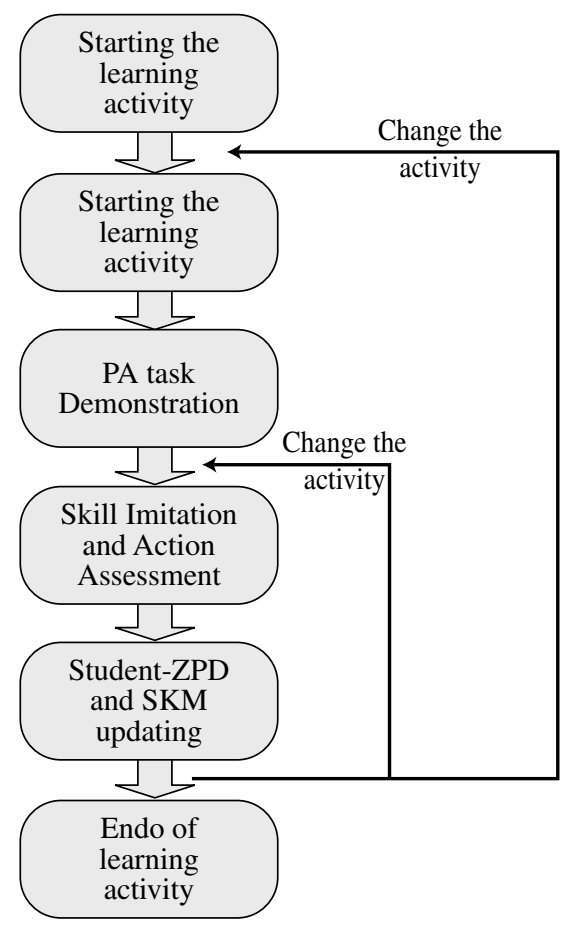

Figure 4. Scaffolding tutoring strategy for PAs in VETs.

We define a RLO design by contract repository in the system which can be accessed by the agents that inhabit the environment and need some knowledge to do their work. The access is facilitated by a mechanism described later which operates over the metadata contract.

Using the RLO concept, we have formulated the SKM and ZPD student's structures [23]; in this way the PA will know what kind of tasks the student is ready to learn and should suggest the appropriate one to each student.

We propose building a binnacle structure in the form of an student personal repository, which can be useful for two objectives: it allows the PA to check frequency, time-consumed and quality (number of successes or failures) of each student's work session and, it provides a main service to the student allowing him/her to review their individual learning history raising the student's 
consciousness about their own apprenticeship, allowing them to internalize it in this way.

While the student is executing an activity, every action executed by him/her must be saved in a record. The PA (the trainer) must communicate the result (success or failure) to the Student Modelling Agent which, through the Historic Agent, will update the student binnacle, the SKM and the ZPD where appropriate. The Student Modelling Agent will be in charge of both updating this repository and answering questions to the student or the Tutoring Agent.

The defined record structure is:

Id-Student, a student identification code

Date, the current date

RLOi-executed, RLO link

Start-time

End-time

Success, a Boolean field

The PA can use this repository to build the student's SKM and to suggest activities to the student (perhaps an activity change will be welcome after some failures doing one). This SKM is defined like a set of components as in ec(1), where each component makes reference to a RLO completed by the student [23]:

$$
S K M=\left\{R L O_{1}, R L O_{2}, \ldots, R L O_{k}\right\} ; \text { where } k \geq 0
$$

The Expert Agent accesses the RLO repository, containing full RLOs, to construct the best procedure to solve the posed problem; the procedure could be seen as a concatenated ñby pre and post conditions- structure of RLO's. Each precondition of RLOi must be satisfied by one (or more) postcondition of $\mathrm{RLO}_{\mathrm{i}-1}$ (or $\mathrm{RLO}_{\mathrm{i}-2}$, etc.), except for the first RLO (initial state) and the last one (the desired outcomes).

All RLOs are accessible to VET agents by their associated metadata, so the best procedure to solve a problem, the SKM and the ZPD will be constructed using these associated RLO metadata.

If the learning objective is reached, the student has acquired a new skill or ability and his/her SKM must be actualized. Additionally, the Student Modelling Agent constructs the student's ZPD based on the student's SKM: the process starts by looking in the RLO repository for the RLOs that can be satisfied in all (or almost all) of their preconditions with the post-conditions of the RLOs that belong to the SKM. Then we can construct the student ZPD as a RLO set as in ec.(2), where each element will reference a specific RLO the student is ready to learn with partner's help [23]:

$$
Z P D=\left\{R L O_{1}, R L O_{2}, \ldots, R L O_{p}\right\} ; \text { where } p \geq 0
$$

Now the PA is able to know what the student is ready to learn and could select the appropriate actions. In this way, the trainer can suggest the student to practice the tasks which he/she needs to reinforce.

2. Activity Selection: The student is free to choose the activity that s/he wants to practice. When the student selects an activity the Tutoring Agent decides if the student is ready to learn the activity, asking the Curriculum Agent for the requirements involved and comparing theses with the student's knowledge and capabilities.

To apply scaffolding successfully in the VET it is necessary to correctly classify the activities and actions (or tasks). According to the AT theory, through practice an action can be transformed into an operation, and an activity can be transformed into an action if new objectives appear or if they change. This dynamic behaviour in a VET can be simulated using the next defined structures; firstly, we can consider an "activity set" -as in ec.(3) and ec.(4)- which defines the different activities available in the VET for the student; secondly, each element belonging to the activity set allows the access to a related "action set", which has all the actions possibly related to an activity, each one properly represented by a RLO:

$$
\begin{aligned}
& \text { Activity set }=\left\{\text { Act }_{1}, \text { Act }_{2}, \ldots, \text { Act }_{\mathrm{j}}, \ldots, \text { Act }_{\mathrm{N}}\right\}, \\
& \text { where } \mathrm{N}>0 \\
& \text { Action set } \mathrm{i}=\left\{\mathrm{RLO}_{1}, \mathrm{RLO}_{2}, \ldots \mathrm{RLO}_{\mathrm{j}}, ., \mathrm{RLO}_{\mathrm{m}}\right\}, \\
& \text { where } \mathrm{i}, \mathrm{j}, \mathrm{m}>0 \text { and "i " refers to the activity “i”." }
\end{aligned}
$$

The division of work shows how the work is distributed in the community. The community is formed by the environment inhabitants: students, PA, agents. The activities in the VET are regulated by rules, rules that are as close as possible to the real ones because the VET is used to train activities than are dangerous or costly in real life.

Defining roles is a simple an effective way to assign activities to different user profiles in the environment. There is a well defined group of intelligent software agents inhabiting the VET [4]; nevertheless, for our tutoring objectives, we considered only the agent which interacts with the students, that is, the PA. The model defines two basic role types: learner and trainer, but each one can be subdivided to allow the participants to play different roles: machine operator, technical support, advanced partner, trainer, virtual partner, for example. 
The user roles could change according to the requirements of the specific VET. A first division could be in three levels of user roles associated with the organizational levels: operational, tactic and strategic. The operational level role is focused on the routine aspects of the task; in a production plant, for example, it focuses on aspects like: put on/get off appropriate suit, follow the security rules, etc. The tactic level role is focused on high level activities, which demand more cognitive effort; in the production plant, for example, to decide whether to activate or deactivate a machine, taking into consideration real parameters. Finally, the strategic level role is trained on activities at higher levels; for example defining directions in emergencies. Each level can have associated many different roles.

The student's activity set will have a limited number of activities according to what the student can do in his/her associated role. This is a limitation to be considered by the PA in a multi-user system; a higher level member could be training tactic and operational levels, but a lower level role can only train the activities associate to this profile. At runtime more than one user can be assigned to the same role, however restrictions can be set on the greatest and least number for each role.

3. PA task Demostration: Once selected one activity, the PA executes a complete action/task demonstration, giving explanations and repeating it any times the student needs. The PA shows the student how to perform the task in a step-by-step way, using other resources available like: the verbalization of the process or problem solving strategy, additional information and libraries. Offering explanations could be implemented in a graphical manner, for example by clicking over machine's components; in this way it is possible to clarify doubts about some topics any times the student needs. This stage is equivalent to the modelling and offer explanations explained by Hogan and Pressley [5], and the modelling stage from Vygotsky.

On the other hand, Vygotsky [3] suggests as a tutoring strategy fully solving the problem just at the beginning of the learning, and then offering partial solutions to the problem or giving cues when the student needs it. A way to implement this in a VET is allowing the full activity demonstration in this third step, but limiting the demonstration in the fourth step "Skill imitation and action assessment" to the action currently performed.

4. Skill Imitation and Action Assessment: The student now has the opportunity to execute the task by him/her self. All over the time the student is executing the task the PA is putting its attention on his/her actions, assessing him/her and ready to give scaffolds if these are needed (repeated failures, too long time without actions, etc.). The amount and types of scaffolds offered could change depending on student's performance; the PA can provide him/her advice, explanations or suggestions invite him/her to do something, ask a question directly, give her/him cues or ideas, etc. If the student is having a good performance, the PA is going to remove the scaffolds and allow him/her to perform the action by him/her self. This stage is directly associated with the skill imitation stage from Vygotsky and Hogan and Pressley [3, 5], and has the goal of providing the learning experience to the student.

Associated with the student training, the PA applies a continuous assessment over the student work, evaluating his/her performance. Good performance permits the student to train other actions; bad performance maintains the student in the same level; the PA could show another view of the problem to facilitate the understanding of it. If all actions within an activity are well executed, the student could change the activity or practice it autonomously any times s/he wants. An activity is finished when the student can it execute correctly without any help; this step can occur at any moment in the training; a student with good skills and abilities probably can perform correctly the task quicker than other with less developed capabilities. The VET gives each student the possibility to train any times s/he needs; the PA will be all the time attending the learning needs and supervising the learner.

As defined in the activity and the action set, the student executes some actions belonging to a defined activity. As the student acquires experience training actions from an activity (we can check in the SKM the number of successfully performed RLOs), the PA extends the time before giving suggestions or explanations, waiting for student's requests, giving the student more autonomy and the possibility to solve the problem by him/her self. Anyway, the number of recent mistakes must be considered before removing the PA help; we can obtain this information from the student's binnacle.

5. Student-ZPD and SKM updating: the PA must apply a continuous assessment (most of the time indirect, through observation) over the learner's actions, and it is in charge of reporting this successes or failures to the Student Modelling Agent because the student-ZPD and the student-SKM need to be continuously updated. Using these SKM and ZPD structures and the other ones previously defined, the PA can check what actions the student could execute (or complete) comparing the RLOs belonging to the ZPD with the RLOs associated with each defined action (ec.5). That is, if:

Action set $\mathrm{j} \cap(\mathrm{S}-\mathrm{ZPD} \cup \mathrm{SKM})=$ Action set $\mathrm{j}$

Then the student is able to execute the action " $\mathrm{j}$ ” 
In the same way, comparing the SKM with each action set, the PA can know what actions have been learnt and determine which activities are complete, which are incomplete and which ones have not been trained at all. To suggest an action to execute, the PA gives preference to the ones related to the activity in course; anyway, if the student decides to change the activity or the action, the PA has the mechanism to offer adequate alternatives.

As one of the main objectives of a VET is to turn actions into automatic by training, and knowing from AT that practice forces actions to become operations, we can consider the SKM like an approximation to an "operational set".

6. End of learning activity: The student can end his/her learning activity when s/he wants to. Even if the PA can check the student's performance anytime it needs, the student will be invited to review a summary about his/ her work session when s/he decides to end the training (and, of course, s/he can review previous sessions if s/he wants to). As we already said, presenting the student an overview about their training performance is a powerful way to meet the goal of having the student in charge of their own progress; in this way s/he can engage her/ himself in an active learning perspective, processing the information in a deeper level of understanding and being able to recognise what $\mathrm{s} /$ he does not know yet. To be conscious of their individual progress provides the student the capability of interiorizing the knowledge, which is an educational goal.

\section{APPLYING THE MODEL}

The proposed model is meant to work over the multi-agent architecture for Intelligent VETs presented by De Antonio, Ram'rez and Méndez [4]. The architecture has been implemented with a combination of quite heterogeneous technologies in the Decoroso Crespo Laboratory at the Universidad Politécnica de Madrid in the context of MAEVIF project (Model for the Application of Intelligent Virtual Environments to Education).

VETs are especially valuable in domains where real life training is very expensive or where students can experience some risky situations, such a maintenance or control of Nuclear Power Plants (NPP). Méndez, Herrero and De Antonio [24] have described two applications for training in NPPs, MAEVIF and PRVIR, which help students to learn how to perform physical, procedural tasks, such as the procedure for entrance in a radioactivity controlled area.

Even if the student has freedom to walk around the environment and select the activity and the actions to do, each action has a very well defined number of steps to be followed, with a clear sequence of RLOs. Lets consider, for example, some activities, actions and roles defined in a NPP which allow us to illustrate the proposed structures:

NPP Activities:

(access_NPP, access_radioactivity_area, operate machine1, ......)

Related Actions:

Access_NPP_Actions=(identification_process,access_ individual_box, put_on_working_suit, put_on_security_ shoes)

Access_radioactivity_area_Actions=(put_on_security gloves, put_on_security_mask, hold_tool)

Related Roles:

\section{Role<learner-operator $>$ \\ Require \\ Lrn.type $=$ operator}

Ensure

Lrn.knows(Access_NPP)

Lrn.knows(access_radioactivity_area)

Lrn.knows(operate_machine1)

...

\section{Role<learner-maintenance $>$}

Require

Lrn.type $=$ maintenance

Lrn.knows(Access_NPP)

Lrn.knows(access_radioactivity_area)

Lrn.knows(operate_machine1)

Ensure

$$
\text { ... }
$$

\section{Lrn.knows(machine_maintenance)}

\section{Role $<$ learner-supervisor $>$ \\ Require}

Lrn.type $=$ supervisor

Lrn.knows=machine_maintence

Ensure

Lrn.knows=performance_supervision

Each action set is composed of several actions that the student has to perform to meet the activity goal. Each action in a VET is described by one RLO, which describes the sequence and the tools used to execute the action correctly in the plant. The RLOs are stored in a repository; each RLO can be accessed through the associated metadata of the contract. 
Not forgetting that there are pre-requisites and postconditions for each RLO, the Access_radioactivity _area_Actions have as pre-requisite the well-executed Access_NPP_Actions; in the same way, having executed well the Access_NPP_Actions gives the student the faculty of walking around the power plant installations.

As the student is working in the VET, the PA is conveying his/her successes and failures to the related agents, in order to update the individual associated Binnacle, SKM_set and ZPD_set. Going on with the previous example, let suppose the following performance of the student, recorded in his/her associated binnacle, showed in table 1:

Table 1. Binnacle.

\begin{tabular}{|c|c|c|c|c|c|}
\hline Id-Student & date & RLOi-executed & $\begin{array}{c}\text { Start- } \\
\text { time }\end{array}$ & $\begin{array}{c}\text { End- } \\
\text { time }\end{array}$ & Success? \\
\hline xx1 & $2007-10-10$ & identification_process & $14: 45$ & $15: 05$ & True \\
\hline xx1 & $2007-10-10$ & access_individual_box & $15: 20$ & $15: 35$ & false \\
\hline xx1 & $2007-10-10$ & access_individual_box & $15: 35$ & $15: 45$ & true \\
\hline xx1 & $2007-10-10$ & wear_working_suit & $15: 50$ & $16: 05$ & true \\
\hline xx1 & $2007-10-10$ & wear_security_shoes & $16: 10$ & $16: 35$ & true \\
\hline$\ldots$ & & & & & \\
\hline
\end{tabular}

As a consequence of the student's performance, some actualization of SKM_set and ZPD_set are done:

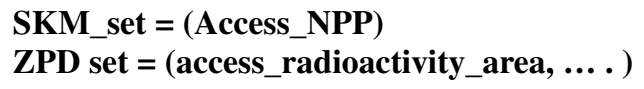

All over the student's learning activities, the PA is tutoring the learner according to both the current strategy step and the student's performance and experience. These are important factors to determine the kind of responses the PA will offer (quantitative and qualitatively).

\section{CONCLUSIONS AND FUTURE WORK}

In the educational context the final objective is for the learner to become independent, having internalized the knowledge required to complete the task. We believe that scaffolding tutoring strategy can be useful to meet this goal and, we have exposed how this scaffolding metaphor might be transferred from the classroom to virtual environments for training and efficiently used by the PA in its tutoring activities, putting special emphasis in transmit the key features of the strategy to its application on VETs.

In scaffolding applied by a PA in a VET, the actions are embedded in the environment and the PA would carry out activities demonstration, performing a complete modelling of the situation and providing a shared understanding of the goal.
All defined structures, mainly based on Activity Theory and Vygotsky's Social Theory, allow the PA to improve its behaviour, turning it more credible.

Using the defined structures Activity_Set, Action_Set, SKM and ZPD, the PA can predict what actions the student could execute (or complete), knows what actions have been learnt and determines which activities are complete, which ones are incomplete and which ones nave not been trained at all. On the other hand, these structures are useful and easy to implement mechanisms.

Assistance to the learner is provided by the PA, "the virtual trainer", in a multimodal manner using the available tools or, depending on the application, by virtual partners. The PA has the mission of play the tutoring role in a several ways: applying ongoing assessment of learner's performance; giving properly feedback; explaining; answering questions; inviting participation; modelling problem-solving with think aloud strategies; removing or changing supports when the learner is performing well some actions of any activity. Scaffolding tutoring strategy features make it dynamic and adaptive, very proper for its applications in VETs.

The implementation of the proposed scaffolding strategy in a VET is currently one of the work lines in the Decoroso Crespo Laboratory at the Universidad Politécnica de Madrid (UPM), in the context of the MAEVIF project (Model for the Application of Intelligent Virtual Environments to Education).

\section{REFERENCES}

[1] S. Kerr. "Virtual Environments for Social Skills Training: The importance of scaffolding in practice". Proceedings of the fifth international ACM conference on Assistive technologies. Assets 2002, pp. 104-110. Edinburgh, Scotland. 2002.

[2] D. Wood, J.S. Bruner and G. Ross. "The role of tutoring in problem solving". Journal of Child Psychology and Psychiatry. Vol.17 Issue 2, pp. 89-100. April 1976.

[3] L.S. Vygotsky. "Mind in society: The development of higher psychological processes". Cambridge, Massachusetts, USA. M.A.: Harvard University Press. 1978.

[4] A. De Antonio, J. Ramírez and G. Méndez. "An agent-based architecture for virtual environments 
for training” In: M.I. Sánchez (ed) "Developing Future Interactive Systems". Hershey PS, USA. Idea Group Publishing, Inc. 2005.

[5] K. Hogan and M. Pressley. "Scaffolding Student Learning: Instructional Approaches \& Issues". Cambridge, USA. Brookline Books, Inc. 1997.

[6] R. Luckin and B. du Boulay. "Ecolab: the Development and Evaluation of a Vygotskian Design Framework". Int. Journal of Artificial Intelligence and Education. Vol. 10 N $^{\circ}$ 2, pp. 198-220. 1999.

[7] J.C. Winnips. "Scaffolding by design: a model for www-based learner support". Ph. D. Thesis. Faculty of Educational Science and Technology, University of Twente. Enschede-The Netherlands. 2001.

[8] S. Puntambekar and R. Hübscher. "Tools for Scaffolding Students in a Complex Learning Environment: What Have We Gained and What Have We Missed?'. Educational psychologist, Vol.40 $\mathrm{N}^{\mathrm{o}}$ 1, pp. 1-12. Lawrence Erlbaum Associates, Inc. 2005.

[9] S. Jackson, J. Krajcik and E. Soloway. "The design of guided learner-adaptable scaffolding in interactive learning environments". Proceedings of ACM Conference on Human Factors in Computing Systems (CHI 98), pp. 187-194. 1998

[10] C. P. Lim and D. Hang. "An activity Theory approach to research of ICT integration in Singapore schools". Computers \& Education, Vol. 41 Issue1, pp.49-63. June 2003.

[11] T. Marsh. "Staying there: an activity-based approach to narrative design and evaluation as an antidote to virtual corpsing”. In: G. Riva, F. Davide, W. a. IJsselsteijn (Eds). "Being there: Concepts, effects and measurement of user presence in synthetic environments". Amsterdan, The Netherlands. Ios Press 2003.

[12] M.Hasu and Y. Engeström. "Measurement in action: an activity-theoretical perspective on producer-user interaction". Int. Journal on Human-Computer Studies. Vol. 53 N $^{\text {o }} 1$, pp. 61-69. 2000.

[13] Y. Engeström. "Learning by Expanding: An ActivityTheoretical Approach to Developmental Research". Helsinki, Finland. Ed. Orienta-Konsultit. 1987.
[14] L. Uden and N. Willis. "Designing User Interfaces using Activity Theory". $34^{\text {th }}$. Hawaii International Conference on System Sciences. 2001

[15] P.R. Polsani. "Use and Abuse of Reusable Learning Objects". Journal of Digital Information. Vol. 3 $\mathrm{N}^{\mathrm{o}} 4$, article $\mathrm{N}^{\mathrm{o}}$ 164. 2003.

[16] B. Meyer. "Object Oriented Software Construction". New Jersey, USA. Prentice Hall, 2nd. Edition. 1997.

[17] S. Sánchez-Alonso and M.A. Sicilia. "Relationships and commitments in learning object metadata". 5th International Conference on Information Technology Based Higher Education and Training. 2004.

[18] S. Sánchez-Alonso, M.A. Sicilia. "On the concept of learning object 'Design by Contract'”. WSEAS Transactions on Systems. Vol. 2 No 3, pp. 612-617. 2003.

[19] IEEE Learning Technology Standards Committee. "Learning Object Metadata". IEEE 1484.12.1. 2002. Acceded: October $30^{\text {th }}$ of 2005 URLs: http://ltsc. ieee.org/wg12/files/LOM_1484_12_1_v1_Final_ Draft.pdf

[20] C. Quintana, J. Krajcik and E. Soloway. "Scaffolding Design Guidelines for Learner-Centered Software Environments". Annual meeting of the American Educational Research Association, New Orleans, L.A.-USA. 2002.

[21] S. Petsangsri. "The Effects of Embedded Scaffolding Strategy in a Cognitive Flexibility-Based Computer Learning Environment". International Conference on Computers in Education (ICCE'02), pp. 75-79. 2002.

[22] S.J. Kerr. "Scaffolding: design issues in single \& collaborative virtual environments for social skills learning". ACM Proceedings of the workshop on Virtual environments. Vol. 23, pp. 81-91. 2002.

[23] R. Imbert and B. Troncoso. "Improving trainer decisions into a CVE for training applying ZPD concept". 5th WSEAS International Conference on Multimedia, Internet \& Video Technologies. Greek. 2005.

[24] G. Méndez, P. Herrero, and de A. Antonio. "Intelligent Virtual Environments for Nuclear Power Plants". 6th International Conference on Enterprise Information Systems, Portugal. 2004. 